\title{
NOTAS SOBRE \\ CULTURA E IMPRENTA EN MURCIA \\ DURANTE EL SIGLO XVIII
}

Cayetano MAS GALVAÑ

Universidad de Alicante 

En un trabajo anterior, tuvimos ocasión de constatar la existencia en Murcia de un importante foco de irradiación del pensamiento jansenista e ilustradd1). Se trataba del Colegio Seminario Conciliar de San Fulgencio. Entre 1774 y 1778 el obispo, a la sazón D. Manuel Rubín de Celis, acometió la reforma de los anteriores planes de estudios e introdujo nuevo profesorado, de modo que hasta 1808 este centro gozó de renombre nacional dentro de dichas corrientes de pensamiento. Pese a las negativas repercusiones del "Plan Caballero", la invasión francesa y la posterior restauración fernandina, el fuerte núcleo jansenista-condenado al silencio-resurgió con fuerza, ahora claramente orientado hacia los postulados liberales, durante el trienio 1820-1823.

Quedó clara, en el trabajo al que aludimos, la escasa influencia que en la reforma ejercieron las distintas fuerzas presentes en el contexto local. Bastó la acción de dos de ellas, en gran medida ajenas al mismo, para llevarla a término: básicamente, la coalición entre un gobierno reformista y un prelado afín a sus principios ideológicos, quien además contaba con un centro emancipado de la tutela de las instituciones y grupos de poder locales. Ahora bien, el importante peso del Seminario en el terreno cultural, de signo ilustrado, no nos autoriza a pensar, por grande que éste haya sido, en la inexistencia de anteriores manifestaciones, por distintas vias, del nuevo pensamiento en la capital del Segura(2). Por otra parte, resulta imprescindible, para efectuar un encuadre adecuado de la cuestion, conocer a fondo la naturaleza y la trabazón básica de la panorámica cultural de Murcia si pretendemos mensurar el carácter, intensidad, alcance y modulaciones particulares adoptadas por las corrientes culturales al difundirse en este medio concreto; asi como el grado de aceptación-leáse las resistencias-alcanzado. En estas últimas direcciones centramos el presente artículo. Constituye, si se quiere, una aproximación más preocupada por los aspectos "externos" de la cultura, explicables desde el plano de las estructuras de una sociedad dada y susceptibles de objetivarse cuantifi- 
cándolos, que por investigar los matices propiamente cualitativos. Por supuesto, no es preciso que manifestemos la reciprocidad de ambas visiones, siempre complementarias, a las que se somete a abstracción sólo con fines analíticos.

Asi pues, la situación cultural que ofrece la ciudad de Murcia durante el siglo XVIII ha sido tratada con mayor o menor profundidad, por un buen número de autores. No obstante, su estudio todavia no se ha abordado de manera sistemática. Un grave obstáculo lo dificultaba: la escasez de monografías sobre los aspectos infraestructurales, que hoy comienza a ser subsanado. De hecho, sólo Flores Arroyuelo ha planteado, desde una visión de conjunto, las claves del problema(3). Tras rechazar esta "leyenda de oropel" que dibujaba una sociedad murciana de idílicos contornos durante el Seteceintos, este autor incide en la respuesta, de signo inmovilista, que proporciono la oligarquía local a la profunda crisis que se abatió sobre la ciudad en los compases finales del Antiguo Régimen. Tal crisis venía a ser el resultado de la progresiva agudización de las contradicciones estructurales puestas de manifiesto por el proceso de crecimiento de finales del siglo XVII y comienzos de la siguiente centuria. La Sociedad Económica de Amigos del País, en torno a la cual centra Flores su estudio, participa con escasos matices diferenciales de las mismas actitudes sostenidas por el concejo municipal. Son prácticamente los mismos individuos, pertenecientes a los grupos sociales privilegiados, los que aparecen en ambas instituciones. Así pues, la conclusión a la que llega Flores coincide, a grandes trazos, con la que obteniamos nosotros respecto del Seminario: la llustración se recibe en Murcia como ideología oficial propugnada por el gobierno. Más aún, y puesto que son las oligarquías locales quienes se encargan de introducirla, no cabía esperar otra cosa que desvirtuaciones, desganas y dilaciones, cuando no resistencias, al mínimo choque con los intereses socioeconómicos de tales elementos.

Por su parte, otros estudios(4) han puesto de relieve la correspondencia existente entre un núcleo de estructuras-económicas, sociales y de poder-mantenidas con escasa variación durante toda la modernidad 
murciana, y la mentalidad inmovilista de las oligarquías locales, controladas por las instituciones municipales(5).

Sin embargo, las afirmaciones precedentes, válidas en tanto que generales, deben verse matizadas en sucesivas investigaciones. Por lo pronto, -es lo que queremos significar-la nómina de los "ilustrados" murcianos no se reduce a los miembros de la Económica. En efecto, en los colegiales fulgentinos y en su profesorado hallamos, al menos a nivel de las individualidades, un núcleo cuya adscripción al pensamiento ilustrado resulta mucho más clara. Además, al aplicar el calificativo "ilustrado" a los miembros de la Económica hemos de tomar el término con suma cautela: hay que tener muy presente la composición social de este organismo en el que predominan, junto al clero y la nobleza local, los cargos y funcionarios de la administración estatal(6). De ahí las dudas que abrigamos en cuanto a que su presencia en las listas de socios responda realmente a una íntima convicción personal. Eso sí, una postura ilustrada clara sólo parece manifestarse en aquéllos de sus integrantes que, de un modo u otro, tienen relación con el Seminario. En todo caso, ambas instituciones representan dos vehiculos muy distintos en la manifestación de las corrientes ilustradas, dada su diferente naturaleza. Será el Colegio fulgentino, sin duda alguna, el que va a llevar el mayor peso en la formación intelectual de los individuos que más tarde evolucionarán hacia el liberalismo (Posadas, Clemencín, Campos...) desde unas posturas muy claramente ilustradas.

Hechas estas acotaciones previas, que nos apartan de cualquier formulación sumaria en cuanto al caso murciano, retomemos las conclusiones expuestas por Flores Arroyuelo. Su interés lo juzgamos tanto mayor en cuanto apuntan en el mismo sentido que, respecto a la interpretación general de la llustración española, apuntaba recientemente el profesor $F$. López. A su juicio, más que estudiar la lucha entre "Luces" y «barbarie, se trata de enfrentarse aquí ante un caso, muy complejo, de subdesarrollo con enormes implicaciones en el dominio de las ideas y de las mentalidades(7). 


\section{FUENTES Y METODOLOGIA}

En esta dirección, no es preciso que indiquemos la importancia que adquieren, en la investigación de los fenómenos culturales, una serie de estudios: procesos de alfabetización e instrucción (y su incidencia en las distintas capas sociales), análisis de bibliotecas (tanto de particulares como de instituciones), sociología de los lectores, etc. No obstante, si estos trabajos apenas se han iniciado a nivel nacional, su carencia es absoluta respecto de Murcia. El aspecto mejor conocido es precisamente la producción editorial, y en torno a ella desarrollamos el presente artículo. Su valor como reflejo e indicador de una realidad cultural, como marco de referencia en el que situar o valorar las corrientes dominantes ( $y$ la aparición de otras nuevas), no ofrece dudas(8). Quede claro, por otra parte, que se trata de una aproximación parcial, cuyos resultados deben contrastarse con los obtenidos en las otras investigaciones de las que acabamos de hacer mención.

Nos hemos basado en el único repertorio bibliográfico con que por el momento contamos: la Biblioteca del murciano, de Pio Tejera, adicionada por Garcia Soriano(9). Recientemente, F. J. Díez de Revenga y M. ${ }^{a}$ Dolores Egea(10), han puesto de manifiesto las limitaciones que presenta la elección de esta fuente. Pese al juicio de Garcia Soriano(11), la nómina de Tejera podría ser ampliada, para el siglo XVIII, en un 400 o 500 por ciento, de modo que en este supuesto trabajariamos sólo sobre un $25 \%$ del total de la producción editorial murciana del periodo elegido, 1700-1800. No es nuestra intención efectuar una crítica bibliográfica o una revisión sobre el particular, tema en el que estos investigadores gozan de indiscutida autoridad. Sin embargo, hemos de lamentar el desconocimiento sobre la naturaleza de las obras a expensas de las cuales tiene lugar el incremento indicado, en tanto no vea la luz un nuevo y más completo catálogo bibliográfico. Hay que dejar sentado, pues, el carácter provisional de los datos que hemos manejado. Lo que no nos impide estimar que cualquier corrección ulterior no alterará gravemente las conclusiones actuales: la muestra nos parece bastante amplia para ser razonablemente significativa. 
Por otra parte, es Iógico que las limitaciones y la falta de datos que presenta la obra de Tejera sobre muchas de las cuestiones de la labor tipográfica, repercutan en nuestro propio estudio. De ahí que nos limitemos a trabajar sobre los datos disponibles, dejando constancia de los aspectos no investigados. Igualmente, un análisis cualitativo profundo tampoco entraba dentro de nuestro propósito. Unido a ello, lo impreciso de algunas de las referencias de Tejera, que quizá pueda haber causado algún que otro error en la clasificación de los impresos. Esto último tiene validez sobre todo en aquéllos que por su solo título o por la escasa diferenciación de los distintos campos-propia de la época-bien pudieran haber sido adscritos tanto a un apartado como a otro.

En el terreno de la metodología, la serie de inconvenientes expuestos también ha incidido negativamente. Este trabajo no constituye, ni pretendía serlo, un estudio bibliométrico profundo. Eso si, se articula sobre los cuadros que se acompañan, en los que abordamos, desde un enfoque exclusivamente descriptivo, el análisis de los datos empíricos. A nuesto juicio tal estudio bibliométrico sólo tendrá plena razón de ser a partir del momento en el que dispusiéramos de un inventario completo de las obras y títulos, de autor murciano o impresas en Murcia.

Así pues, nuevamente se ve reforzado el carácter limitado del estudio que sigue. En el primero de los cuadros, fundamento de los restantes, se pretende una clasificación de los impresos desde un doble horizonte: la división en grupos y áreas dentro de cada grupo; y la cronológica. Respecto de la primera, hemos optado por establecer la clásica distribución en cinco campos (religión, historia, derecho y jurisprudencia, bellas letras, ciencias y artes)(12). En cuanto a las distintas áreas, parecerá excesivo su detalle. Se ha pretendido, al presentarlo así, poner en evidencia las significativas lagunas que apreciamos en los distintos ámbitos. En sentido contrario, la abundante cantidad de cédulas, pragmáticas y ordenes reales, normas, reglas, constituciones, ordenanzas, etc., queda incluida-aunque de modo diferenciado-en el seno del tercer grupo, el de Derecho y jurisprudencia.

En lo referente a la clasificación cronológica, resulta difícil respetar el criterio decenal. Se observará, en este sentido, la presencia de algunos 
periodos (1700-1729; 1740-1759; 1760-1780, y 1780-1800), más extensos, colocados a continuación de los propiamente decenales. En ellos tienen cabida los impresos que, sin contar con la fecha de edición, sí reseñan el nombre del impresor. En consecuencia, se corresponden con los períodos de actividad de alguno de ellos (Jayme Mesnier, Felipe Diaz Cayuelas, Nicolás José Villagordo, Felipe Teruel y Viuda de Felipe Teruel, respectivamente), y los totales que arrojan deben ser adicionados a los de los distintos decenios. Por tanto, se restringe la posibilidad de establecer una periodización rigurosa que no sea la excesivamente amplia de 1700-1729, $1730-1759$ y $1760-1800$, con lo que se difumina en gran medida la evolución coyuntural.

Unas últimas notas previas. Sólo se ha considerado el conjunto de impresos salidos de los talleres tipográficos murcianos, sea cual fuere el origen de su autor. Es decir, lo que en la investigación bibliométrica viene denominándose impresos. Las obras, publicadas por los autores murcianos en otras ciudades, precisarian por sí solas una intensa labor sólo para poder ser exhumadas. Por lo demás, nuestro fundamental interés-la situación local-nos ha llevado a prescindir incluso de plantear la cuestión. En cambio, sí se apreciará una divergencia en los totales de impresos según uno u otro cuadro. Este hecho obedece a la diferencia entre el número de impresos y el número real de títulos. De este modo, los 404 impresos producidos en los 101 años que abarca el período se ajustan estrictamente al número de los registrados por Tejera, cuando vienen a corresponderse con 399 títulos distintos. La diferencia, de tan solo 5 impresos cuyo título se repite por diversas razones (reediciones, versiones en distintas lenguas...), responde a una doble consideración, según se trate de efectuar el análisis de los impresores o de los autores. Nuestro interés por mantener los registros de Tejera nos ha impulsado, pese al riesgo de cometer una incorrección, a considerar como un mismo impreso los publicados en varios tomos.

Los cuadros 2, 3 y 4 resumen el anterior desde distintos puntos de vista: seguimiento de la evolución por grupos y periodos, significación absoluta y relativa de cada campo y área respecto del total, y distribución del conjunto de impresos por periodos de publicación. En cuanto a los cuadros 5,7 y 8 , se ocupan del análisis de los autores, productividad per- 
sonal (empírica), encuadre social y especialización por campos. Los números 10,11 y 12 hacen lo propio respecto de los impresores. En fin, el 6 y el 9 procuran cuantificar el número de libros y folletos, en función del número de páginas, y como resumen de estos distintos aspectos. Hay que hacer dos salvedades por lo tocante a los cuadros. Se trata de! importante núcleo de impresos en los que falta algún dato ( $y$ en cada caso lo hacemos notar), así como de la falta de ajuste hasta el $100 \%$ de los totales porcentuales, dado que hemos despreciado las milésimas.

Otras cuestiones no encuentran reflejo en los cuadros. Asi, por ejemplo, no se ha establecido una jerarquía de los impresos en cuanto a sus distintos niveles de accesibilidad. Empero, se hacen las oportunas referencias en el texto, siendo, por otra parte, que no existe aún una metodología definida sobre el particular(13).

\section{LOS IMPRESOS}

En la contemplación global de los tres primeros cuadros, referentes a los impresos, una primera nota destaca. Se trata del abrumador predominio de los impresos comprendidos en el primer campo, el de religión. Por si solos, copan más del $48 \%$ del total, es decir, prácticamente la mitad. Aspecto éste que también han destacado Díez y Egea, a cuyo trabajo venimos haciendo referencia(14). Dominio al que, además, podemos adicionar las obras de historia sagrada y eclesiástica (4\% del total)(15), de derecho y legislación canónica (10\%), de poesía y teatro sagrado (2\%), con lo que el conjunto de impresos más o menos directamente vinculados a la temática religiosa rebasa el $65 \%$. Y esto sin tener en cuenta las obras que, en cantidad no determinada, quedan afectas a una perspectiva impregnada de matices y concepciones religiosas. A la vista de lo indicado por Díez, podemos pensar que estas proporciones no se verán muy alteradas ni aun tomando en cuenta el porcentaje de impresos omitidos por Tejera.

La evolución de este grupo a lo largo del siglo realza todavía más su importancia. El incremento constante en el total de impresos, de 71 (17001729) a 217 (1760-1800), es seguido, ajustándose sin apenas desviaciones, por las obras religiosas (de 34 a 105), con 10 que mantienen su peso específico sin apenas retroceso: del $57^{\prime} 62$ a $56^{\prime} 75 \%$. 
Dentro de las áreas de este campo, la constituida por los impresos de piedad y devoción domina totalmente el panorama: un $93 \%$ (45\% sobre el total). Como se desprende del cuadro 1, tienen cabida en él las obras de moral, los sermones y los relatos de intención hagiográfica, destacando los dos primeros, con 89 y 69 impresos. Debido a la escasa magnitud de las cifras que se manejan al descender a estos niveles de concreción, resulta más difícil y susceptible de error procurar distinguir aqui una evolución concreta. Sin embargo, y a pesar de su aumento, parece apuntar una tendencia de descenso relativo en los sermones, y de sostenimiento, también relativo, en los morales y hagiográficos.

La falta de variación en la composición interna de este grupo se ve acompañada por la monotonía que apreciamos en el terreno cualitativo. Conviene destacar(16) el carácter específicamente circunstancial común a casi todos estos impresos: sermones compuestos en conmemoración de festividades locales, celebraciones de todo tipo, honras fúnebres; pastorales de los obispos, novenas, triduos, septenarios..., abundantemente representados, no hacen más que poner de manifiesto el grado de sacralización de una sociedad tradicional, cual es la murciana de aquellos momentos, y la profundidad que reviste la intervención clerical en múltiples aspectos de la vida cotidiana. Circunstacialidad y localismo incontrastados que nos descubren la función de este grupo de impresos-tengamos presente que es el más abundante-, concebidos bien para el discurso oral, al que en principio sirven, bien para su lectura y difusión entre capas sociales muy amplias. De gran interés será conocer, a este efecto, la evolución seguida por el número de personas capaces de acceder a estas obras, pero en todo caso nos vemos remitidos al nivel más bajo, a la frontera entre la transmisión oral tradicional y la letra impresa. El carácter básico que subyace aquí, por tanto, resulta claro. Se trata del control ideológico y del sostenimiento del prestigio social, tomado en un sentido amplio y no estrictamente religioso, que ejercen los estamentos privilegiados sobre sí mismos, pero ante todo sobre las masas, a través del grupo social que recibe tal función, es decir, el eclesiástico. Mencionemos, abundando en ello, que la única lengua en que aparecen es, salvo muy contadas excepciones-en favor del latín-, la castellana. Ni en este ni en ningún otro campo, existen obras impresas en otras lenguas distintas, siendo la proporción de las que usan el latín muy escasas (cuadro 12). 
El conjunto de la producción religiosa se completa con una serie de obras que vienen a confirmar cuanto decimos. Se trata de un abundante bloque compuesto por manuales para uso de predicadores, misioneros, confesores, ejercicios espirituales para comunidades religiosas, libros de coro, breviarios, misales, y obras de índole similar. Algunos títulos pueden proporcionarnos una idea acerca de su condición: Sermón en la celebridad de la proclamación de nuestro católico monarca $D$. Carlos IV, de Fr. Carlos Morata(17); La lealtad testimoniada de la muy noble ciudad de Murcia a D. Carlos Tercero, de Fr. José Antonio Funes(18); El César, el Emperador, el Rey de Murcia, San Patricio, aclamado en su día, de Fr. Pedro Sánchez(19); Explicación clara y comprendiosa de toda la doctrina christiana distribuida en quarenta y seis pláticas predicables para missión, de Fr. Diego Camuñas(20); Sentencias varias... para entrar predicando por las calles en los pueblos donde se va a misión, del P. Pedro Calatayud(21); Novena del Gloriossisimo S. Juan Bautista(22); Devoto septenario a las siete palabras(23); Brevis confessariorum instructio(24); Exercicios espirituales para todos los días de la semana(25); Suma de exercicios devotos breves y fáciles(26); Vida del Venerable Padre y Doctor Subtil Fr. Juan Dunsio Escoto(27); Vida de la Venerable Virgen Franciscana Maria de la Xara(28)...

Dos notas, pues, podemos aventurar sobre el carácter de estos impresos. De un lado, la vigencia de los modos propios de la religiosidad barroca, exterior y masiva, preocupada sobre todo por controlar y reorientar las manifestaciones del sentimiento religioso, y por evitar cualquier desviación supuestamente heterodoxa entre los estratos sociales menos cultos. De otro, representan el mayor nivel de difusión social de los impresos, a la vez causa y efecto de su predominio respecto de los restantes grupos. No podemos dejar de ver en tal vigencia, un reflejo de la situación que se advierte en el terreno de las infraestructuras.

Esta cuestión adquiere mayor relieve si intentamos establecer un paralelismo entre el caso murciano y la evolución a nivel nacional. Con tal objeto, nos hemos servido de los datos ofrecidos por F. López, quien ha efectuado tres sondeos quinquenales (1721-1725, 1741-2745, y 1784-1788) sobre los anuncios comerciales que libreros y autores insertaban en la Gaceta de Madrid. Así, la situación de partida en el primer quinquenio es muy semejante a la murciana, con más de la mitad de las obras en el grupo de 
religión, y pobreza total en los restantes. Sin embargo, de modo paulatino, en los dos últimos quinquenios se alcanza una situación final muy distinta. A causa del aumento de las categorías de Ciencias y Artes y de Bellas Letras, la de Religión queda relegada a un más modesto $35 \%$. Comparado con el caso francés, se aprecia el retraso de España en el proceso de autonomización de los campos del saber y de las disciplinas científicas respecto de la concepción teologica de raigambre medieval(29).

En cuanto a Murcia, la resistencia al cambio es aún mayor. Así, ya se ha visto que no cabe hablar de una evolución descendente de los impresos de indole religiosa. Excluida la legislación (cuadro 2), aumentan claramente-en posición relativa-los grupos de Historia y Bellas Letras, pero el Derecho y las Ciencias evolucionan en sentido descendente (en términos absolutos también, y en ambos campos durante el período 1760-1800, pese a las alzas iniciales).

En este ambiente, pues, en el que la religiosidad tradicional conserva plena vigencia, los ecos de las Luces, en un campo tan decisivo como éste, llegan tarde y de modo amortiguado. Nos referimos a las contadas obras, escritas por los colegiales y profesores del Seminario de San Fulgencio. Aquí, como fruto de las reformas episcopales, sí podemos observar el abandono de la teología escolástica y del aristotelismo filosófico que la fundamentaba. Al mismo tiempo, aparece la preocupación por la reforma de la predicación, así como una nueva perspectiva teológica: sin dependencia de las escuelas, centrada en el estudio dogmático con base en la Escritura y en los Santos Padres. Entre ellas: Ars vere philosophandi sive logica rationalis, de la que no nos consta el autor(30); las tesis de algunos colegiales, como la de D. Carlos Clemencín(31); y las obras de los profesores valencianos Ilamados por Rubín de Celis, un Tomás Fuentes (Oratio de humanarum disciplinarum usu ad theologian, Oratio de theologiae studii optima ratione)(32), o un Francisco Javier Romeu (De Sacrae oratoriae dignitate adserenda)(33). A su vez, éstas son las únicas obras que van a cubrir, muy parcialmente, el anterior vacio existente en las obras de carácter propiamente teológico. Con todo, en su mayor parte sólo son tesis para su lectura en los actos públicos de fin de curso. Por tanto, se limitan a elaborar algunas conclusiones sobre los textos establecidos para el estudio en el Colegio. $Y$ aún así, las escasas conclusiones originales que contienen 
tropezaron con una abierta oposición por parte de sus detractores, incluida la denuncia ante el Santo Oficio(34). Esto es, la aparición en Murcia de los exponentes del nuevo pensamiento fue tan extraña al contexto cultural como también lo fue la reforma del Seminario. Que las consecuencias de ésta tuvieron una repercusión muy limitada se comprueba con una simple referencia a un hecho sucedido en 1787. En ese año, durante el mes de abril, el famoso P. Diego José de Cádiz realizó una "santa misión" en Murcia, rodeado-si damos crédito a los relatos que la narran--de un enorme fervor popular y de la tremenda expectación que siempre le acompañaba. Más aún, su visita tuvo lugar justo durante el breve pontificado de D. Felipe Miralles, que se sitúa entre los de Rubín de Celis y López GonzaIo, los dos prelados más claramente ilustrados que ocuparon la sede cartagenera. Pues bien, el obispo Miralles nombró al celebérrimo capuchino, perseguidor de ilustrados donde los hubiere, "su Teólogo Consultor y de Cámara; Examinador Ordinario del Obispado, y Catedrático de Teologia en el Seminario Conciliar de San Fulgencio de esta Ciudad»(35). Por suerte, el P. Cádiz continuó su camino y Miralles expiró el año siguiente.

Como se ha señalado, la inferioridad numérica de los impresos de los restantes campos halla una primera explicación en su propio carácter. Se trata de saberes especializados, que exigen una mayor instrucción o grado cultural entre sus cultivadores y lectores. De ahí que su menor difusión social se imponga como primer condicionante de la debilidad a la que nos referimos. No obstante, la falta de datos sobre la cuestión nos obliga a permanecer dentro de las generalidades. Ahora bien, y con algunos matices, el planteamiento que se ha apreciado en el grupo de religión resulta aplicable también en estos otros: la introducción del pensamiento ilustrado, portador de un nuevo concepto de la cultura, tropieza con graves dificultades que lo reducen a manifestaciones esporádicas y vacilantes. En definitiva, estamos de nuevo ante la escasa permeabilidad de la sociedad murciana, que por otra parte no contaba, v. gr., con una tradición universitaria o científica, y que se traduce en las desvirtuaciones a las que nos hemos referido al hablar de la Sociedad Económica de Amigos del País. Con todo, esta ausencia no sería lo más significativo: habria que investigar profundamente, ante todo, la naturaleza de los elementos que determinaron una evolución como la que estamos esbozando. 
Así, la Historia será uno de los campos que registra un mayor aumento a lo largo del siglo. De un solo impreso entre $1700-1730$, se pasa a 27 en 1760-1800. Pero ello no debe inducirnos a cometer un error de apreciación. Los cuatro impresos publicados entre 1730 y 1759 (siempre según Tejera) (cuadro 2), encubren apenas dos títulos. Y en cuanto a los 27 de la última etapa, que bien podrian hacernos pensar en una auténtica eclosión historiográfica, crean una falsa imagen. Diecinueve no son más que unos opúsculos de 24 páginas en $4 .^{\circ}$ que, comenzando con el título genérico de Historia verdadera..., escribió D. Hilario Santos Alonso. Por citar algunos títulos: Historia verdadera y espantosa del Juicio universal del mundo, La soberbia castigada. Historia verdadera y exemplar de Esther, Historia verdadera de la conversión del Reyno de Francia a la Fe de Jesuchristo, Historia verdadera del falso y perverso profeta Mahoma, Historia verdadera y extraña del Conde Fernán González...(36). Como se ve, se trata de unas obritas portadoras de una concepción de la historia abierta a la penetración de elementos extrínsecos a la misma, escasamente emancipada del tradicional finalismo: su propósito fundamental es moralizante y ejemplarizador. De ahi que llegue a resultar dudosa su inclusión, en rigor, dentro de este grupo de impresos. El resto de las que lo componen son suficientemente conocidas (las del canónigo Lozano, Fr. Leandro Soler, Fr. Pascual Salmerón...) y tienen un mismo denominador, el de la historia local o regional. En consecuencia, nos hallamos ante un conjunto de escaso peso, no obstante su incremento secular, y que debe ser tomado con mucha cautela en cuanto a su enjuiciamiento. Hecha abstracción de los folletos escritos por Santos Alonso, hay que estudiar a fondo las restantes obras a fin de comprobar sus fundamentos metodológicos y las concepciones historiográficas en las que sus autores se mueven. Aparentemente, tenemos referencias contradictorias. Ya de por sí, resulta muy significativa la aparición de esta generación de historiadores regionales. Así, no cabe duda de la conciencia e intención renovadora de un impresor, Francisco Benedito, de probable ascendencia italiana(37). El fue quien sacó de sus prensas la serie de Historias verdaderas (sea cual fuere su contenido), así como la reedición de los Discursos históricos de Cascales, anteponiéndole un prólogo en el que criticaba la confianza que el humanista habia concedido a los falsos cronicones al tiempo de transcribir una cita de Mayans sobre el 
particular(38). A Benedito, por lo demás, lo encontraremos más adelante en esta misma linea ilustrada. Además, no podemos soslayar la Crónica de la Santa Provincia de Cartagena, de Fr. Pablo Manuel de Ortega, quien como corresponsal de Mayans había hecho gala de una clara orientación crítica(39). Pero en el extremo opuesto, Fr. Leandro Soler estructuró su Cartagena de España ilustrada(40) sobre lo ya realizado por Cascales hacia más de un siglo. La consulta del índice de la obra parece demostrar una clara intención apologética y localista por parte de este autor. De nuevo, por tanto, tropezamos en este campo con la constante de la pervivencia de una concepción historiográfica que no ha conseguido emanciparse plenamente de los viejos esquemas. El localismo y la sacralización, la dependencia respecto de intenciones extrínsecas asi como su escaso número, nos alejan mucho de los nuevos presupuestos que la crítica impuso en este terreno, de la secularización y de la emancipación de la Historia como disciplina autónoma.

En un mismo grupo hemos incluido tanto el Derecho, como la legislación y el conjunto de normas (constituciones, reglamentos, ordenanzas, etc.), de valor jurídico. Tal asociación, realizada por motivos prácticos, podria contribuir a desdibujar el movimiento real en este campo, razón por la que en el cuadro 2 quedan excluídos los últimos, es decir, todos los impresos emanados de los órganos con capacidad legislativa, tanto civiles como eclesiásticos, (cédulas, pragmáticas, ódenes reales; edictos y bandos municipales; constituciones de congregaciones religiosas, concordias capitulares, mandatos episcopales, etc.) que ya de por sí representaban el $56 \%$ del total del grupo. El resto viene a cubrir solamente el $11 \%$ del global, con lo que su peso pasa a equipararse al del grupo de Bellas Letras. Se trata, casi siempre, de memoriales de pleitos y de informaciones de derecho, civiles y canónicos, redactados por los abogados y relatores con ocasión de los numerosos pleitos, en los que suele subyacer el componente económico. Como se indico, este grupo presenta una peculiaridad diferencial. Hasta 1759 mantiene su importancia relativa, aumentando de 14 a 24 impresos. Pero en el periodo 1760-1800 sufre un fuerte descenso ( 8 impresos), que le relega a ocupar algo más de un $4 \%$ en este último corte sincrónico. Preferimos dejar constancia del fenómeno, antes que aventurar explicaciones sobre sus causas. Desde luego, seria necesa- 
rio, primero, medir la cantidad de obras no anotadas por Tejera, para luego comprobar si este descenso se corresponde con un fenómeno real que apuntase, por ejemplo, hacia una disminución en los niveles de conflictividad con reflejo jurídico dentro de la sociedad murciana.

Como es lógico, el carácter local y pragmático da el tono a estos impresos, más todavía que en otros campos. Son realmente escasas las obras que se elevan por encima de los casos particulares, aunque nunca pierden el contenido pragmático. Reseñemos, en este sentido la de Fr. Pascual Salmerón, De Benignitate in opinando anticuorum sapientium... Dissertatio juridica, legalis et canonica(41), y la del licenciado D. Pascual Lozano y Vicente, Consulta sobre la institución hereditaria universal fideicomisaria(42).

También en alza constante, las Bellas Letras llegan a representar en 1760-1800 casi un $20 \%$ del total. Su composición es heterogénea. Así, damos cabida desde los planes de estudio, como los de Rubín de Celis, o los de Miguel Antonio de Molina (sobre la creación de unos colegios para formación de militares)(43), hasta algunas piezas oratorias, cartas morales inspiradas en valores nobiliarios(47), cartillas y uartes" de gramática para uso de escolares, así como una variada serie de relaciones en las que resulta evidente su intención apologética y de prestigio, esta vez por cuenta del concejo municipal. Las más veces fueron compuestas en ocasión de solemnidades y fiestas, dando cabida a gran cantidad de poemas, por lo común de escaso valor. Incluímos también la literatura de creación en general, aunque las referencias de Tejera al respecto son bastante reducidas. Diez y Egea se han encargado de poner este hecho de manifiesto, ocupándose extensamente de este apartado(45). En efecto, las omisiones cometidas por D. Pío parecen más significativas que en otros ámbitos. Se le habrian escapado seis novelas de Marmontel, publicadas por Benedito entre 1788 y 1789, así como tres comedias en italiano del mismo impresor(46). Cabría añadir la no poco intrigante noticia que Garcia Soriano recogió de Cassou(47), en la que daba cuenta de la impresión, en 1768 de la tragedia Zaïre, obra volteriana, traducida por D. Fulgencio Labranche para ser representada en casa de un particular. Por último, mencionemos la tragedia Coriolano, de Pedro Matías Martínez de la Junta(48) y un poema escrito por D. Ignacio López de Ayala que se publicó en latin y castellano en 
1777, bajo el título Termas de Archena, y dedicado, dato revelador, "a la erudita juventud del colegio de San Fulgencio de Murciaw(49). Estas dos obras sí aparecen en Tejera. De nuevo, para centrar la importancia cualitativa de este grupo, especialmente en cuanto a modelos e influencias, se precisaría un detallado estudio de cada obra. Por nuestra parte, nos limitaremos a señalar, en paralelo a la decadencia de las tradicionales "justas poéticas" de clara herencia barroca, una evolución sensible a la penetración de las fórmulas neoclásicas(50). Al mismo tiempo, el interés por el conocimiento de las citadas obras de Marmontel y Voltaire, aun cuando se trate de algunas de sus producciones más inocuas (no olvidemos las condenas inquisitoriales que pesaban sobre las obras de estos autores(51). No obstante, estas impresiones no debieron tener mayor trascendencia que el abastecimiento de las élites regionales, más o menos cultas, que-como en otros terrenos-estaban recibiendo en proporción difícilmente mensurable la influencia de las nuevas formas culturales. Pese a estos avances, al contemplar el conjunto de las obras que componen este apartado debemos seguir constatando ausencias muy importantes. Prácticamente todo lo publicado no es más que literatura de diversion y entretenimiento. Por el contrario, no asoma ningún indicio de interés por la crítica filológica, o, en suma, por el humanismo.

Ahora bien, desde la perspectiva por la que hemos optado resulta del mayor interés analizar la dialéctica, siempre presente, que se establece entre el autor y sus lectores, entre el autor y el contexto social en el que desarrolla su producción. A partir de ahí, será cuando podrán ser aplicadas las oportunas correcciones que permitan establecer un enfoque definitivo de la realidad cultural que nos interesa. Pocos medios tan sensibles a este proceso como la prensa perídica, punto medio del contínuo encuentro que ha de producirse entre el redactor y su público para posibilitar la supervivencia de la obra(52). En efecto, la aparición de los periódicos en 'Murcia va a ser, otra vez, tardia. A partir de 1792, verán la luz el Diario de Murcia, el Correo Literario, las Tardes de Roque Pio...(53). El segundo de los citados alcanzará un nivel ciertamente importante. Publicado durante más de tres años, bisemanal, llegó a contar con 429 suscriptores. De ellos, sólo un $30 \%$ vivían en la ciudad de Murcia y casi la mitad lo hacían fuera de su reino. Abundan éstos sobre todo en Andalucia, Valencia y Cataluña, pero 
no faltan en Madrid, Castilla, País Vasco y Galicia(54). Tampoco contamos, con ningún estudio detallado sobre el particular, a pesar de las abundantes citas dispersas en las obras que más o menos directamente han rozado el asunto(55). Empero, existe unanimidad entre los autores en un mismo punto: el carácter conservador, por decirlo de algún modo de esta prensa, de concepción miscelánea, situada a caballo entre la divulgación con miras pedagógicas y formativas, la simple noticia, y un tipo de sátira social que recuerda, siquiera de lejos, la línea de sus hermanos mayores los espectateurs de Guinard(56). Dicho carácter se explicaría por múltiples razones, que podemos reducir a dos: el ambiente generado por los sucesos revolucionarios de Francia y la propia naturaleza del conjunto de sus lectores, hasta el punto de que aquél se imponía como "necesario" por mera cuestión de supervivencia. Pero, sin perjuicio de comprobar, efectivamente, las posturas políticas pro-absolutistas mantenidas unos años más tarde por sus redactores - caso de D. Luis Santiago Bado-ello no nos autoriza a negarle a su obra el carácter sinceramente ilustrado que destila en los terrenos en que le fue posible: la literatura, la ciencia, la historia y la religión. Desde una encendida defensa de la navegación aerostática, hasta el intento por publicar una obra histórica por entregas (procurando corregir los errores cometidos por Cascales y Hermosino)(57); así como la censura literaria ejercida de acuerdo con los cánones neoclasicistas y el esfuerzo por armonizar razón y fe, desdeñando los excesos provocados por la irreligiosidad, la superstición y el escolasticismo. En cuanto a las posiciones políticas, no será preciso recordar que para tantos ilustrados el divorcio entre los postulados y la práctica del absolutismo, y las corrientes que ellos mismos encarnaban, sólo pudo hacerse claro, en las mentes de una minoria, durante la década crítica que medió entre el inicio del nuevo siglo y las Cortes de Cádiz. El caso de Ramón Campos, estudiado por Elorza, a pesar de ser curioso no deja de resultar muy significativo: este personaje, discípulo y profesor del seminario, conocedor entre otros de Condillac y Smith, aúna el liberalismo económico con la defensa de la sociedad estamental(58).

A la vista de todo lo expuesto, especialmente por lo tocante a este terreno de las Bellas Letras, hemos de dar, pues, la misma importancia a la presión restrictiva ejercida desde diversos puntos como a la propia 
ausencia de un núcleo ilustrado surgido de la evolución de los factores actuantes en la estructura social murciana. Como suele ocurrir se trata sobre todo de causas-efectos, más que de causas simples, lo que está en la base de estas posturas ambiguas.

Desde este punto de vista, se comprende mejor la penuria que contemplamos al revisar el último de los grupos, el de Ciencias y Artes. Serán 25 impresos en todo el siglo, representando algo más del $6 \%$ del total. Más aún, tras un discreto aumento en las dos primeras etapas, conocerá un descenso, en cifras relativas y en cifras absolutas, razón por la que en los últimos cuarenta años del siglo XVIII los impresos de este grupo no llegan a alcanzar el $5 \%$ respecto del total. En su estructura interna predominan los escritos médicos (algunas obras sobre el uso de las aguas y el valor de ciertos manantiales locales, una Cartilla Phisiológica de inspiración galenista, las Constituciones de la Academia Médica murciana y las obras del interesante Dr. Miravete), y las obras de matiz económico (desde el Memoria/ sobre los impuestos de la sal, de Belluga, hasta unas Advertencias para los criadores de seda, de Fr. Francisco Pellicer, asi como algún manifiesto para subsanar errores en la percepción de impuestos. De hecho, estos dos tipos de obras son las únicas existentes hasta 1759. Se trata de la persistencia de la literatura arbitrista, por un lado, y por otro, del desarrollo de una ciencia que no conoció grandes trabas durante nuestro siglo

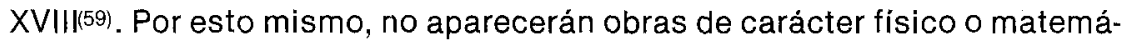
tico hasta que se rebasa ampliamente las décadas centrales de la centuria. Así pues, el menor número corresponde a las artes y técnicas aplicadas (una obra de náutica y otras sobre defensa contra inundaciones y desagües), y a las ciencias puras. De nuevo nos encontramos aquí con Romeu, en cuya De Phisicae experimentalis praestantia et utilitate(60), preconizaba la utilización del método inductivo y empírico, y con el polifácético Bado, buen matemático y astrónomo (Compendio matemático y Demostración fiel del futuro Eclipse de Sol(61). Cabria añadir la obra matemática de D. Juan Bañón, que no reseña Tejera, y los no pocos escritos científicos que publicase el Correo Literario.

Aún así, las ausencias siguen siendo tan evidentes para la mente del observador que no es preciso señalarlas. Si las Letras contaban, al menos en un sentido escasamente especulativo, con cierto auditorio, las 
Ciencias-incluso en sus terrenos menos problemáticos-no tenian prácticamente quien las escribiese ni quien las leyese. En este sentido, sólo la exhumación de las biblietecas revelaria el grado de interés por las ciencias-y por cualquier otro campo-en la Murcia de la llustración.

\section{AUTORES E IMPRESORES}

En los cuadros $5,7,8$ y 9 , como se advirtio en su momento, damos cabida a los datos de que disponemos referentes a los autores, necesario complemento de las notas destacadas al tratar de sus obras. De ahí que las características que acabamos de reconocer hallen fiel reflejo en este otro terreno. Así, de los 399 títulos, 301 cuentan con autor diferenciado, mientras que no tenemos el dato en 34 casos y otros 64 son fundamentalmente de índole legislativa o normativa (cuadro 9). Contando, pues, con las 301 de autor individual, y hecho inventario de los que escriben 20 más (52, el $28 \%$ ), vemos reducida la nómina de autores a 182, de los que 130 tienen en su haber una sola obra (cuadro 9). Más interesante resulta atender a su naturaleza. De los 182, 120 (el $66 \%$ ) son eclesiásticos, religiosos regulares en su mayoría ( $46 \%$ del total), mientras que solo 15 son laicos-con predominio de los médicos-, y en otros 47 casos (26\%) no se especifica el dato. Con toda seguridad dentro de este último grupo se hallan incluidos los autores de casi todos los impresos, en los que se indica comúnmente su titulación académica, pero no su estado. Tampoco resulta ocioso señalar la correspondencia entre los porcentajes de impresos de matiz religioso, que se extendía a un $65 \%$ de las obras, y el de los autores eclesiásticos (66\%) con lo que acaba por delimitarse con toda nitidez la importancia de este estamento en el terreno cultural.

Dominio que se acentúa al proceder al análisis del grado de especialización, a fin de verificar en qué medida se da la autonomá entre los distintos campos, utilizando este mismo criterio que parte de los autores. De los 52 que escriben varias obras, 36 trabajan en un solo campo (25 en religión), y 16 en dos o más. La asociación más común será (cuadro 5) entre la religión y cualquiera de los otros (13 casos). Esta situación general, en la que los regulares ostentan el papel más destacado, se plasmará también en 
otros aspectos de la realidad cultural murciana, como, v. gr., el absoluto monopolio que estos religiosos ejercieron sobre la enseñanza secundaria y superior(62), a la par que explica, al menos desde este enfoque parcial, la beligerante oposición que éstos vinieron a sostener ante las reformas fulgentinas. Por otra parte, serán los propios eclesiásticos seculares los portadores de una concepción nueva de los saberes, no plenamente autonomizada, pero sí enajenada de la dependencia escolástica, con todo lo que ello conlleva en cuanto a la socavación de las estructuras tradicionales del Antiguo Régimen.

Un último dato, quizá de menor trascendencia, ilustra este apartado de los autores, y que incumbe a su prolijidad (cuadros 5 y 8). Sólo dos alcanzan cotas realmente elevadas, D. Hilario Santos Alonso (de quien ya hemos visto que se trata sólo de folletos), y el célebre Cardenal Belluga (sobre el que no es preciso extendernos), con 19 y 20 obras respectivamente. Otros nueve se mantienen entre las 4 y las 6 obras: algún abogado (D. Matías Rossique, D. Antonio Martínez Talón), algún obispo (D. Tomás José de Montes), y unos cuantos clérigos oficiando como historiadores (Fr. Pablo Manuel de Ortega, o el canónigo Lozano). En fin, la mayoria de los 52 (un $78 \%$, es decir 41), con más de una obra, producen en torno a 203 títulos(63).

Quedan por analizar las cuestiones tocantes a los impresores y a la variada problemática, local y general, que incidia sobre la impresión. Aun cuando la lista de impresores no ha sufrido variaciones, en orden a nuevos descubrimientos(64), no podemos decir que sean tan conocidos otros muchos aspectos. En principio, no es preciso recordar la influencia fuertemente restrictiva ejercida por la legislación que afectaba al libro y a la imprenta en general: licencia, tasa, monopolios sobre algunas parcelas-como la del rezado eclesiástico-, que los Borbones heredan de la anterior dinastía, así como la dureza en la aplicación de las ya de por si desmedidas penas, que colocaban a los impresores en una insalvable situación al menor paso poco afortunado que diesen(65). Igualmente han quedado también claros los esfuerzos que durante el siglo sostuvieron algunos impresores en favor de la supresión de algunas cuestiones muy gravosas, y el impulso liberalizador y de adecuación a las nuevas circunstancias proporcionado por los gobiernos de Carlos III. Esto sin tener en 
cuenta los múltiples factores de todo tipo (sociales, técnicos, culturales, políticos, económicos) que afectaban de un modo o de otro la labor tipográfica, pero casi siempre en un sentido poco favorable. Con todo, es innegable el crecimiento experimentado durante el Setecientos que, a la postre, provocará los cambios en el nivel legislativo.

Por otra parte, Tejera y García Soriano dibujaron a grandes rasgos los perfiles vitales de los impresores murcianos(66). Lamentablemente, ningún estudio posterior ha venido a utilizar nuevas fuentes, a pesar de que el propio Garcia Soriano señalase, hace ya tantos años, la importancia de explotar, en este sentido, la documentación contenida en los protocolos notariales(67). Como resultado, nos encontramos en el mismo punto en el que aquel investigador nos dejase, en asunto tan elemental. Por lo que nos to$\mathrm{ca}$, incidiremos sobre algunas cuestiones que estimamos dignas de ser destacadas, aunque quizá no avalados en la medida de lo deseable por una base documental amplia y suficiente.

Lo que más salta a la vista es la bajísima productividad media anual que se desprende del cuadro 4. Justo 4 impresos-año, como media general de todo el periodo. Naturalmente, se trata de un indice que, de ser cierto, haría por completo inviable la existencia de cualquier empresa tipográfica. Aplicada la oportuna corrección que señalan Díez y Egea, la media se elevaría hasta unos 16 o 20 impresos-año, cifra mucho más verosímil. No obstante, para apreciar su exacto valor, convendrá efectuar alguna comparación con otros centros de esta industria. Por otra parte, tendriamos que estudiar también la magnitud de la demanda social de bienes de este tipo, es decir-volvemos a ello-, la cantidad y naturaleza de las bibliotecas, así como la extensión del mercado para el que trabajan los talleres tipográficos murcianos, sus principales clientes o sus «mecenas», por así decirlo.

No cabe duda del incremento secular en la productividad. Por desgracia, las bajas que se advierten en algunas décadas (en especial, 1750-1759), no pueden ser puestas en relación con ningún otro fenómeno debido a la cantidad de impresos que no conocemos: Por supuesto, !a mejora secular, económica y legislativa, regional y nacional, hubo de producir resultados beneficiosos sobre los impresores. En cambio, la comparación 
con otras ciudades es aún más problemática. Así, si aplicamos-procedimiento éste en exceso artificioso-, sin discriminación, el incremento del $450 \%$ a cualquiera de las décadas, y lo contrastamos con los datos de que disponemos para otras ciudades durante el periodo 1745-1755(68), la capital del Segura alcanzaría un nivel de producción semejante al de Valencia, lo que no deja de ser excesivo: entre 1700 y 1808 , vieron la luz en esta última ciudad 342 impresos, solo en el terreno científico(69). Es decir, que el esclarecimiento de la pujanza real de la imprenta murciana a lo largo del siglo XVIII depende tanto de las investigaciones que se realicen en torno a ella, como de los que se centren sobre la producción editorial en otras ciudades.

Por el momento, nos inclinamos por relativizar cualquier afirmación sobre el esplendor de la imprenta murciana de aquella centuria, sin perjuicio de suscribir totalmente la mejora secular. Algunos indicios parecen venir en abono de cuanto decimos. En primer lugar, la mitad de los impresos son folletos (cuadro 6). Además, Murcia no parece poder dar cabida simultánea al trabajo de más de 203 talleres, tanto en la primera mitad del siglo, con las sagas de los Mesnyer o los Díaz, como en la segunda mitad, con los Teruel alternando con Santamaría, Muñiz y Benedito. No deja de resultar curioso ver como, comenzado el siglo con un Vicente Llofríu desaparecido de la escena en 1711, rápidamente lo sustituyen, en sucesión ininterrumpida, José Diaz, Felipe Díaz y Felipe Díaz Aguado, quienes trabajan desde 1717 hasta 1760. A su vez, son suplantados por los Teruel (padre, viuda e hijo), desde esa fecha hasta fin de siglo. Paralelamente, los Mesnyer (Jayme, Juan y Francisco), desde 1707 hasta 1746, cuyo hueco se rellena con pocas discontinuidades por Nicolás Villagordo (1746-1760), Benedito y Muñoz-Santamaría. En cuanto a la causa de la desaparición de la imprenta del Convento de San Francisco, en 1765, muy probablemente resida en la Real Orden que prohibía a las comunidades religiosas el sostenimiento de talleres tipográficos(70).

Así pues, se configura sin lugar a dudas el carácter artesanal y familiar de estos talleres, lo que nos lleva a pensar en los cortos límites del mercado al que abastecían, que no llegó a generar, ni siquiera como tentativas, la constitución de formas de explotación económica más desarrolladas. Sobre este mismo aspecto, sería necesario conocer, asimismo, la 
politica seguida por el concejo municipal respecto de los impresores, sobre la cual sólo tenemos algún dato para la centuria anterior(71). Además, tampoco existe certeza sobre si realmente llegó a constituirse un gremio local de libreros e impresores, aunque no lo parece dada la escasa entidad numérica del grupo. Otros datos abonan la hipótesis: la penuria técnica y económica, que se extiende al menos hasta las primeras décadas del XVIII, y que se tradujo durante el siglo XVII en la necesidad de costosos desplazamientos en busca de tipos(72), en la itinerancia o la duplicidad (establecimientos simultáneos en Murcia y Orihuela, actividad complementaria como libreros), o en el interés de los impresores por conseguir la titulación de rango oficial por la Ciudad, el Obispado o el Santo Oficio(73), a la sazón sus mejores clientes. También sería necesario conocer las fuentes de aprovisionamiento de papel, y el origen, por lo común bastante oscuro, de los impresores, así como sus fortunas particulares.

Aunque este estado de cosas mejora durante la segunda mitad del siglo, no aumenta el numero de impresores: ¿trabajaban los talleres anteriormente muy por debajo de su capacidad productiva, se introducen mejoras técnicas, el limitado crecimiento de la demanda no sostenía un mayor número de talleres...?. Estos extremos nos resultan por completo desconocidos. Mientras no surjan datos en contra (no olvidemos las poquísimas reimpresiones, de las que hemos contabilizado sólo 13; a de obras impresas en latín, 28), y a la vista de los impresos, la imprenta murciana gozó de un mercado exclusivamente regional, incluyendo algunas poblaciones de! sur del vecino Reino de Valencia (Orihuela en especial). De hecho, el único momento en el que aparece clara una trascendencia nacional de la imprenta murciana es con la aparición del Correo Literario, precedida de una disputa entre los impresores Muñiz y Viuda de Teruel, al intentar esta última captar para su taller al grupo de redactores del anterior Diario de Murcia(74). Precisamente una de las causas que estaban en la base del fracaso comercial del Diario era su corto mercado(75). Durante los años que siguen a 1792, el Correo llega a convertirse, como indica su larga duración para la época, uno de los mejores negocios editoriales habidos durante el siglo en Murcia. Asi lo daba a entender su principal animador, Bado, cuando en una carta dirigida al Consejo de Castilla, el 19 de julio de 1794(76), manifestaba que su periódico «ha merecido la maior aceptación en todas las Provincias 
de España, y cuya propagación ha contribuido considerables intereses a la Real Hačienda". Y, a pesar de todo, cuando la cuestión económica funcionaba bien, las trabas legales seguian dificultando la prosperidad de la empresa. Así lo manifestaba en el mismo documento D. Luis Santiago, para terminar solicitando la concesión del privilegio de impresión. Caso de haberse producido el fallo del Consejo, no hemos logrado dar con él, pero el Correo se extinguio, sin motivos aparentes, en 1795.

Llegado el momento de recapitular, recordemos las importantes lagunas que existen tanto en el estudio de la imprenta en Murcia como en otras cuestiones colaterales, de las que hemos ido dejando constancia. No era nuestra intención profundizar en su esclarecimiento, sino dejarlas planteadas.

Lo único que, a nivel general, ofrece una mínima solidez son los contornos de la imagen que la cultura tuvo en Murcia durante el siglo de las Luces. Y decimos contornos porque, evidentemente, la imprenta no lo es todo. En nueștro caso, ha sido sólo un medio de aproximación. A través de él ha quedado delimitada la situación de una ciudad periférica, provinciana y cerrada sob̄re sí misma, como tantas otras que restan por estudiar. La mentalidad trảdicional, fuertemente enraizada en todos los estamentos, subsistió-dominó-sin apenas verse alterada, a la oleada ilustrada. El nuevo pensamiento, pese a tener representantes de calidad, penetró débilmente y en un contexto hostil. Pero, sin embargo, no llegó a ser erradicado, ni siquiera con la dura represión a la que fue sometido el Seminario fulgentino en tiempos de Fernando VII. El texto que transcribimos, en extremo sugerente, evoca to profundo de la ruptura que los ilustrados, por mojesta que fuera su influencia, había producido en los esquemas monolíticos de aquella sociedad.

"Y antes de algún otro filósofo, (decía en 1815 el prior del Convento de Santo Domingo elogiando a sus alumnos para denostar la reforma de San Fulgencio), se tomaban los conocimientos necesarios no para hacer la carrera de filosofos, ni brillar en el mundo literario con las luces de la razón, sino para formarse buenos Theologos;... instruidos en toda Ciencia de Dios, en la Ciencia de los Santos..., y aunque muy vacios de las letras que matan, muy llenos del espíritu que edifica y que miraron siempre con aborrecimiento y miran oy la ciencia animal, carnal, mundana, diabólica, enemiga de Dios, no queriendo saber más que lo que conviene... tan bendita doctrina, la del maestro Guillermo Thou, Wiclef, Calvino, jansenistas y liberales...,(77). 


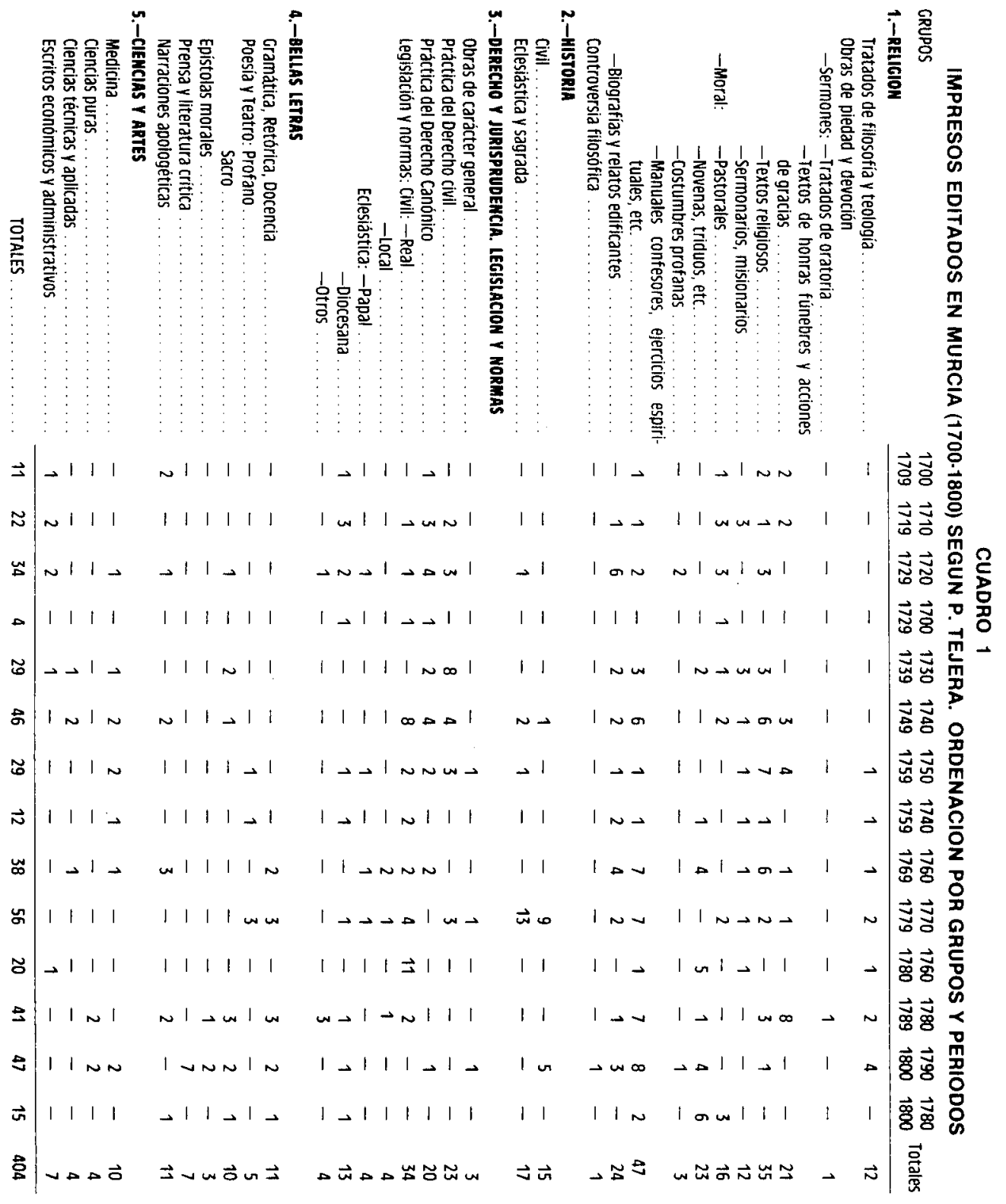




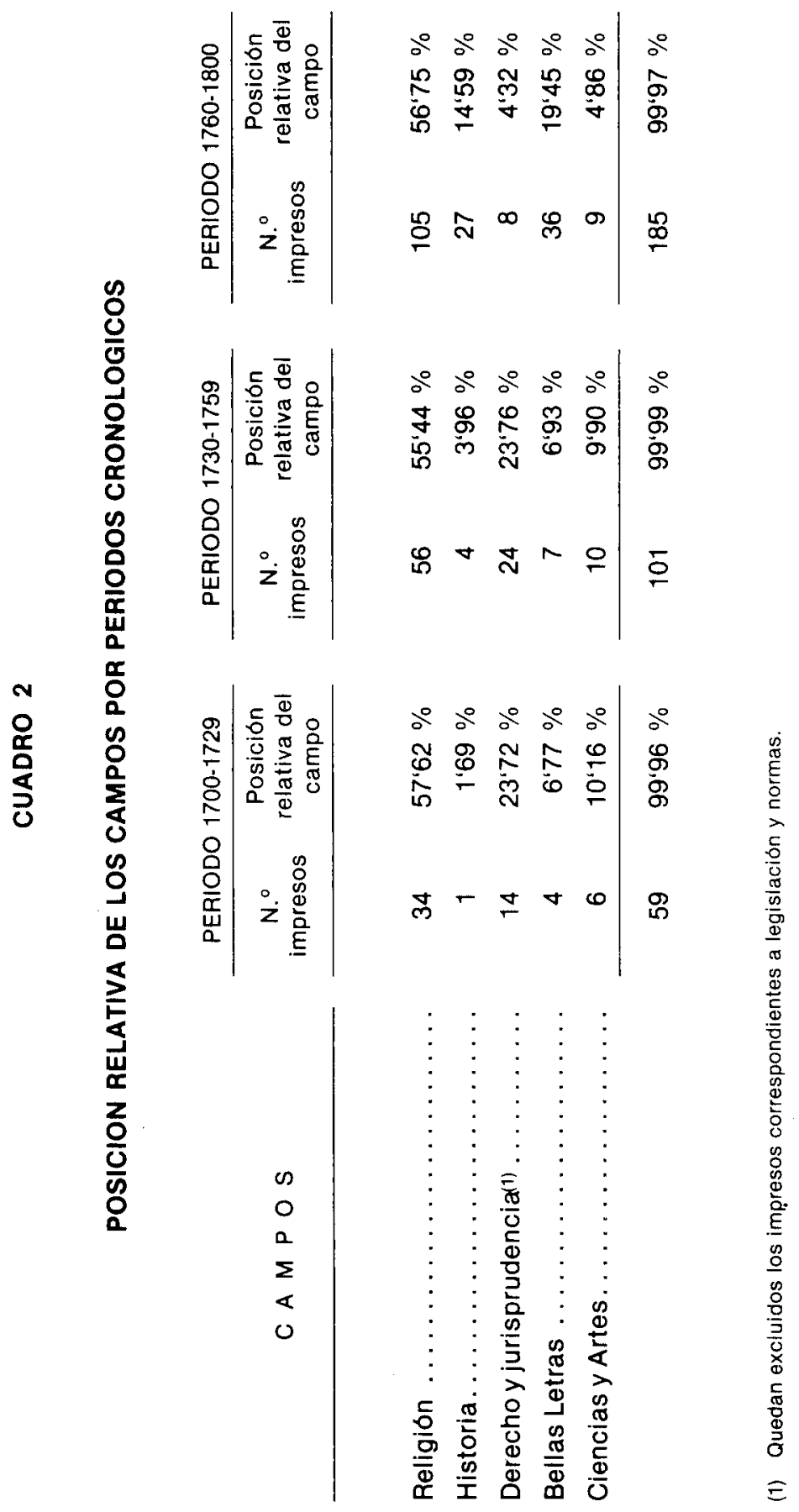




\section{CUADRO 3}

\section{RESUMEN CLASIFICACION POR CAMPOS}

\section{CAMPOS Y GRUPOS}

RELIGION

Tratados Filosofía y Teología .

Piedad y devoción . . . . . . . . .

Controversia

HISTORIA

Civi

Sagrada y Eclesiástica

DERECHO. JURISPRUDENCIA.

LEGISLACION

Generales

Práctica Derecho Civil

Práctica Derecho Canónico ...

Legislación y Normas .

BELLAS LETRAS

Gramática, Poesia, Docencia .

Poesia y Teatro

Epístolas Morales

Prensa y crítica

Narraciones apologéticạs

CIENCIAS Y ARTES

Medicina

Puras

Aplicadas

Escritos económicos

\section{N. ${ }^{\circ}$ Impresos}

$\%$ Total

$\%$ de su campo

195

$48^{\prime} 26$

$100 \times 00$

12

2‘97

$6 \cdot 15$

182

$45^{\circ} 04$

93 ‘33

$0 ‘ 24$

$0 ‘ 51$

32

$7 \times 92$

$100 \times 00$

15

3'71

$46 ' 87$

17

4'20

5312

105

$25 ‘ 99$

$100 \cdot 00$

3

$0 \times 74$

2'85

23

5‘69

$21 ' 90$

20

4'95

$19^{\circ} 04$

59

$14^{\prime} 60$

$56 ، 19$

47

$11^{\prime} 63$

$100 \times 00$

11

272

$23 \times 40$

15

371

$31 ' 91$

3

0574

6،38

7

$1 ' 73$

$14 \times 89$

11

272

$23^{\prime} 40$

25

6'18

$100^{`} 00$

10

2447

$40 ` 00$

0.99

$16^{\circ} 00$

0‘99

$16^{\circ} 00$

173

$28 ` 00$ 
CUADRO 4

DISTRIBUCION POR PERIODOS DE PUBLICACION

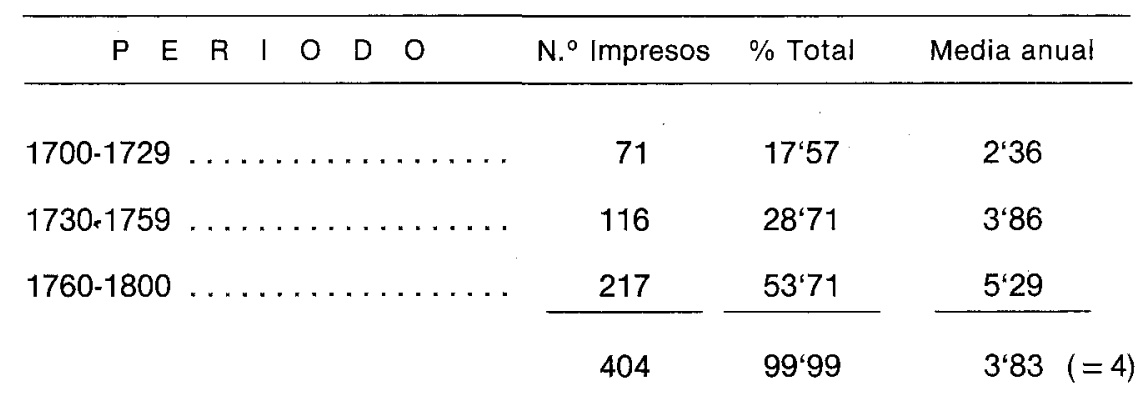


CUADRO 5

ESPECIALIZACION DE LOS AUTORES

(Autores con más de un título)

\begin{tabular}{|c|c|c|c|c|}
\hline N. ${ }^{\circ}$ titulos & $\%$ del Total & N. ${ }^{\circ}$ de campos & N. ${ }^{\circ}$ de autores & \\
\hline \multirow[t]{3}{*}{$2 / 3$} & $78 ' 84$ & 1 & 30 & \\
\hline & & 2 & 11 & \\
\hline & & & & 41 \\
\hline \multirow[t]{4}{*}{$4 / 6$} & $17 \cdot 30$ & 1 & 5 & \\
\hline & & 2 & 3 & \\
\hline & & 3 & 1 & \\
\hline & & & & 9 \\
\hline \multirow[t]{3}{*}{$19 / 20$} & $3 \times 84$ & 1 & 1 & \\
\hline & & 3 & 2 & \\
\hline & & & & 2 \\
\hline TALES. . & $99 \times 98$ & & & 52 \\
\hline
\end{tabular}

Autores que trabajan en un solo campo ....... 36

$69 \times 23 \%$

Religión.................. 25

Derecho, Jurisprudencia ........ 6

Bellas Letras............... 3

Ciencias y Artes .............. 1

Historia . . . . . . . . . . . . . . 1

Autores que trabajaban en varios campos ...... $16 \ldots \ldots 3076 \%$

Religión e: ................. 13

Historia ............ 6

C. y Artes............. 2

Derecho.............. 2

B. Letras ............. 1

Ciencias y Bellas Letras .... 1

Derecho y ciencias ....... 1

Historia y: ................ 2

Derecho.............. 1

Bellas Letras . . . ....... 1

Derechoy: .................. 1

Ciencias . .......... 1 


\section{CUADRO 6}

\section{CLASIFICACION DE LOS TITULOS POR EXTENSION EN PAGINAS}

\begin{tabular}{|c|c|c|}
\hline Títulos con más de 50 páginas . ............... & 131 & $32 ‘ 83 \%$ \\
\hline Títulos con menos de 50 páginas. & 199 & $49 ` 87 \%$ \\
\hline No se especifica el dato. & 69 & $1729 \%$ \\
\hline TOTALES & 399 & $99 ‘ 99$ \\
\hline
\end{tabular}




\section{CUADRO 7}

\section{NATURALEZA DE LOS AUTORES}

Eclesiásticos

Regulares

Seculares

Colegiales ......... 4

Obispos .......... 9

Capitulares ........ 8

Papas

$21 \times 60 \%$

120

$46 \times 70 \%(2)$

$6 \cdot 50 \%$

$2 \cdot 19 \%$

$4994 \%$

$439 \%$

$109 \%$
Laicos

Médicos

Gramáticos

Militares

Cargos y oficios administración estatal y municipal

$16.60 \%$ $0.54 \%$

$320 \times 00 \%$ $1^{\prime} 64 \%$ 15 


\section{CUADRO 8}

\section{PRODUCTIVIDAD DE LOS AUTORES}

\begin{tabular}{ccc}
\hline N. ${ }^{\circ}$ de impresos & N. ${ }^{\circ}$ Autores & $\%$ \\
\hline 1 & 130 & $71 ‘ 42 \%$ \\
2 & 28 & $15 ‘ 38 \%$ \\
3 & 13 & $7 ‘ 14 \%$ \\
4 & 6 & $3 ‘ 29 \%$ \\
5 & 1 & $0 ‘ 55 \%$ \\
6 & 2 & $1 ‘ 10 \%$ \\
- & - & $0 ‘ 55 \%$ \\
19 & 1 & $0 ‘ 55 \%$ \\
20 & 1 & $99 \times 98 \%$ \\
TOTALES... & 182 &
\end{tabular}

CUADRO 9

RESUMEN DE AUTORES, N. ${ }^{\circ}$ DE IMPRESOS $Y$ N. ${ }^{\circ}$ DE TITULOS

Total de impresos registrados . . . . . . . . . . 404

Total de títulos(1) . . . . . . . . . . . . . . . . . . . 399

N. ${ }^{\circ}$ de títulos con un solo autor $\ldots \ldots \ldots \ldots \ldots \ldots \ldots 301 \quad(75443 \%)$

$\mathrm{N} .^{\circ}$ de títulos en que no consta autor $\ldots \ldots \ldots \ldots \ldots .34 \quad(8.52 \%)$

Otros (textos legislativos, colectivos) ........... $64 \quad$ (16'04\%)

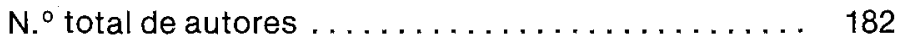

Autores con más de un título ............... $52 \quad(28 \times 57 \%)$

Autores que trabajan en varios campos .......... $16 \quad(879 \%)$

Autores con un solo título ................. $130 \quad(71442 \%)$

(1) Una vez excluídas reimpresiones, obras editadas en varias lenguas, etc. 


\section{ESPECIALIZACION DE LOS IMPRESORES}

\begin{tabular}{|c|c|c|c|c|c|c|}
\hline \multirow{2}{*}{ I $M P R E S O R$} & \multicolumn{5}{|c|}{$C A M P O S(1)$} & \multirow{2}{*}{ OTAL } \\
\hline & 1 & 2 & 3 & 4 & 5 & \\
\hline Vicente Llofriu( $/ 1711) \ldots \ldots \ldots$ & 4 & - & - & 1 & 1 & 6 \\
\hline Jayme Mesnier (1731/36) & 14 & - & 8 & 2 & 3 & 27 \\
\hline José Díaz Cayuelas (1717/1738) . . . . & 12 & 1 & 1 & 2 & 2 & 18 \\
\hline Juan Martínez Mesnier (1731/36) . . . & 1 & - & 3 & - & 1 & 5 \\
\hline Fco. José López Mesnier (1740/46) . & 3 & 3 & - & 1 & 2 & 9 \\
\hline Felipe Diaz Cayuelas (1740/57) & 20 & - & 7 & 4 & 1 & 32 \\
\hline Joseph Fandos Ximeno (1746/48) . . & 1 & - & - & - & - & 1 \\
\hline Nicolás J. Villagordo $(1746 / 60) . . .$. & 8 & 1 & 7 & - & 3 & 19 \\
\hline Imp. Convento S. Fco. (1753/65) . . . . & 6 & - & - & 1 & - & 7 \\
\hline Felipe Diaz Aguado (1760/70) . . . . . & 2 & - & 2 & - & - & 4 \\
\hline Felipe Teruel $(1760 / 80) \ldots \ldots$. & 39 & 1 & 18 & 5 & 2 & 65 \\
\hline Francisco Benedito (1772/80). . & 4 & 21 & 1 & 2 & - & 28 \\
\hline Antonio Santamaría (1784/91) & 1 & - & - & 1 & - & 2 \\
\hline Vda. de Teruel (1781/99) . . . . . . & 40 & 2 & 7 & 20 & 5 & 74 \\
\hline Muñiz y Santamaría (1788/91) & 3 & - & - & - & - & 3 \\
\hline Manuel Muñiz (1791- $\quad$ ) . . & 5 & 2 & 1 & 1 & 1 & 10 \\
\hline Juan Vte. Teruel (1800- $\quad) \ldots \ldots$ & 2 & - & - & 1 & - & 3 \\
\hline Sin impresor. & 28 & 1 & 50 & 6 & 3 & 88 \\
\hline Dudosa clasificación(2) & 2 & - & - & - & 1 & 3 \\
\hline TOTALES & 195 & 32 & 105 & 47 & 25 & 404 \\
\hline
\end{tabular}

(1) 1-Religión; 2-Historia; 3-Derecho y Legisiación; 4-Bellas Letras; 5-Ciencias y Artes.

(2) Algunos impresos dan el nombre del impresor, pero su atribución resulta poco clara en atención a que la fecha que se proporciona no corresponde con los años de actividad de aquél. 
CUADRO 11

CLASIFICACION DE LOS IMPRESOS POR EXTENSION E IMPRESOR

\begin{tabular}{|c|c|c|c|c|c|c|}
\hline I MPRESOR & $\begin{array}{c}\text { Más } \\
50 \mathrm{pp} .\end{array}$ & $\begin{array}{l}\text { Menos } \\
50 \mathrm{pp} .\end{array}$ & $\begin{array}{c}\sin \\
\text { datos }\end{array}$ & Total & $\%$ & $\begin{array}{l}\text { Productividad } \\
\text { anual }\end{array}$ \\
\hline & & & & & & Impresos \\
\hline Vicente Llofríu .... & 4 & 1 & 1 & 6 & $1 \cdot 48$ & $0 ‘ 53$ \\
\hline Jayme Mesnier . . . . . . . & 7 & 15 & 5 & 27 & $66^{\prime} 68$ & $1 ' 22$ \\
\hline Joseph Diaz Cayuelas . ... & 5 & 5 & 8 & 18 & 4445 & $0 \times 81$ \\
\hline Juan Martínez Mesnier . . . . & 3 & 2 & - & 5 & $1 \cdot 23$ & $0 ‘ 83$ \\
\hline Fco. J. López Mesnier . . . . & 3 & 6 & - & 9 & $2 \cdot 22$ & $1 \cdot 28$ \\
\hline Felipe Diaz Cayuelas ...... & 13 & 17 & 2 & 32 & $7 ‘ 92$ & $1 \cdot 77$ \\
\hline Joseph Fandos Ximeno.... & 1 & - & - & 1 & $0 ‘ 24$ & 0.33 \\
\hline N. J. Villagordo Alcaraz .... & 12 & 6 & 1 & 19 & $4 \times 70$ & $1 ; 26$ \\
\hline Imp. Convento S. Francisco & 5 & 1 & 1 & 7 & $1 ‘ 73$ & $0 ‘ 53$ \\
\hline Felipe Díaz Aguado . . . . . . & 1 & 3 & - & 4 & 0.99 & 0336 \\
\hline Felipe Teruel . . . . . . . . . . & 14 & 40 & 11 & 65 & 16.09 & $3 \times 09$ \\
\hline Francisco Benedito . & 8 & 18 & 2 & 28 & $6 \sqrt{ } 93$ & $3: 1$ \\
\hline Antonio Santamaría... & 1 & 1 & - & 2 & 0.49 & $0: 25$ \\
\hline Vda. Felipe Teruel . . . . . . . & 29 & 26 & 19 & 74 & $18 \cdot 32$ & $3 \times 89$ \\
\hline Muñiz y Santamaría . . . . . . . & 2 & 1 & - & 3 & $0 ‘ 74$ & 0.75 \\
\hline Manuel Muñiz . & 7 & 1 & 2 & 10 & 247 & $1^{\prime} 00$ \\
\hline Juan Vicente Teruel . . . . . . & 1 & 2 & - & 3 & 0.74 & $3^{\circ} 00$ \\
\hline Sin impresor ..... & 15 & 53 & 20 & 88 & $21 \cdot 78$ & 0.87 \\
\hline Dudosa clasificación ...... & - & 2 & 1 & 3 & $0 \times 74$ & $0 \times 02$ \\
\hline TOTALES $\ldots . .$. & 131 & 200 & 73 & 404 & $99 \cdot 94$ & \\
\hline
\end{tabular}




\section{CUADRO 12}

\section{CLASIFICACION POR PERIODOS Y CAMPOS DE LOS IMPRESOS EN LATIN}

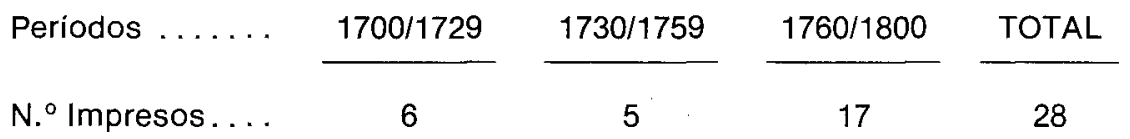

\begin{tabular}{lrrrrrr} 
Campos....... & 1 & 2 & 3 & 4 & 5 \\
\cline { 2 - 6 } N. ${ }^{\circ}$ impresos.... & 19 & 2 & 5 & 1 & 1 & 28
\end{tabular}

N. ${ }^{\circ}$ de impresores: 9. 


\section{NOTAS:}

(1) "Jansenismo y regalismo en el Seminario de San Fulgencio de Murcian. Anales Universidad Alicante. Historia Moderna. N. ${ }^{\circ} 2$, 1982, pp. 259-290.

(2) Baste recordar las figuras de Zapata, Macanaz, Floridablanca, todos nacidos en el reino de Murcia. Por otra parte, la existencia de un grupo científico renovador mediado el siglo ha sido puesta de manifiesto por C. M. ${ }^{a}$ CREMADES GRIÑAN, "la llustrísima Academia de Medicina murciana como foco ilustrado en la España reformista», Monteagudo, n. ${ }^{\circ} 81,1983$, pp. $23-34$.

(3) F. J. FLORES ARROYUELO, "Sociedad Murciana e Ilustración", en Murgetana, n. ${ }^{\circ} 49$, 1977, y en edición separada de la Academia Alfonso X El Sabio, p. 19.

(4) Cf. M. T. PEREZ PICAZO, G. LEMEUNIER, F. CHACON, Materiales para una Historia de Murcia en los tiempos modernos, Universidad de Murcia, 1979.

(5) C. M. ${ }^{a}$ CREMADES GRIÑAN, Estructura, economia y fiscalidad del Concejo murciano en la primera mitad del Setecientos (1701-1759). Tesis doctoral mecanografiada, Universidad de Murcia.

(6) F. J. FLORES ARROYUELO, loc. cit., pp. 17-18.

(7) F. LOPEZ, "Rasgos peculiares de la llustración en España», en Mayans y la llustración. Simposio Internacional en el Bicentenario de la muerte de Gregorio Mayans, Valencia, 1981, Tomo II, p. 636.

(8) Pueden consultarse los trabajos de J. M. LOPEZ PIÑERO. Una bibliografía de referencia, en su obra Ciencia y Técnica en la sociedad española de los siglos XVII y XVIII, Labor, Barcelona, 1979.

(9) Biblioteca del Murciano, o Ensayo de un Diccionario Biográfico y Bibliográfico de la literatura en Murcia, Editorial Garcia Enciso, Madrid, 1941. La base de nuestro trabajo es la sección tercera, "Ensayo de un catálogo de los libros impresos en Murcia", tomo Il, pp. 211-725.

(10) F. J. DIEZ DE REVENGA y M. a DOLORES EGEA MARCOS, "La imprenta y los impresores en la Murcia del siglo XVIIl", en Francisco Salzillo y el Reino de Murcia en el siglo XVIII, Editora regional, Consejeria de Cultura, Com. Autónoma de Murcia, 1983.

(11) Loc. cit, p. 725.

(12) Estimamos esta clasificación como la más adecuada. Cf.F. LOPEZ, Juan Pablo Forner et la crise de la conscience espagnole au XVIIleme. siécle, Inst. d'Etudes Ibériques et Ibéroaméricaines, Universidad de Burdeos, 1976, p. 67 y ss.

(13) Ibid. p. $64-80$ y $474-479$.

(14) Op. cit, p. 56-58.

(15) Normalmente, despreciaremos los decimales en el texto del artículo.

(16) Lo mismo señalan también DIEZ y EGEA, op. cit.

(17) Viuda de Teruel, 1787 , en $4 .^{\circ}$ Cf. TEJERA, loc. cit., p. 444.

(18) Phelipe Teruel, 1760,39 p. más 7 h., en $4 .{ }^{\circ}$ Cf. TEJERA, loc. cit. p. 32.

(19) Phelipe Diaz Cayuelas, 1748,31 p. más 14 h. en $4 .^{\circ} \mathrm{Cf}$. TEJERA, loc. cit. p. 552.

(20) Vicente Llofriu, 1711,307 p. más 7 h., en $4 .^{\circ}$ Cf. TEJERA, loc. cit. p. 272.

(21) Joseph Diaz Cayuelas, 1734, 44 p. más 1 h. en $4 .^{\circ}$ Cf. TEJERA, loc. cit., p. 261.

(22) Felipe Teruel, S. A., 22 p. en $8^{\circ}$, Cf. TEJERA, loc. cit. p. 464. 
(23) Fr. Francisco de San Juan de la Cruz, por Felipe Teruel, 1768,16 p. en $8 .^{\circ}$. Cf. TEJERA, loc. cit. p. 547.

(24) Dr. D. Francisco Gómez Manzanilla y Belluga, por N. J. Villagordo Alcaraz, 1748, 300 p: más $16 \mathrm{~h}$. en folio. Cf. TEJERA, loc. cit, p. 351.

(25) Sin autor, por Felipe Teruel, 1765, 280 p. más 16 h. en $8 .^{\circ}$. Cf. TEJERA, loc. cit. p. 332.

(26) Sin autor, por Manuel Muñiz, 1791, 183 p. más $16 \mathrm{~h}$. en $8 .^{\circ}$. Cf. TEJERA, loc cit., p. 567.

(27) Fr. Pablo Manuel de Ortega, sin impresor, 1748, en 8. ${ }^{\circ}$ Cf. TEJERA, loc. cit., p. 476.

(28) Fr. Juan de Monreal, por José Díaz, 1724, en $4 .^{\circ}$. Ct. TEJERA, loc. cit. p. 441.

(29) F. LOPEZ, Juan Pablo Forner et..., loc. cit.

(30) Sin autor, sin año, por Felipe Teruel, 144 p. más 3 h. en $8 .^{\circ}$. Cf. TEJERA, loc. cit., p. 227.

(31) Cf. TEJERA, loc. cit., p. 286.

(32) Ibidem, p. 340.

(33) Ibidem, p. 518.

(34) Son varias las alegaciones fiscales y expedientes que se conservan relativos a estas denuncias en el Archivo Histórico Nacional, Sección «Inquisición".

(35) Cf. TEJERA, loc. cit., p. 524 y ss.

(36) Ibidem, p. 554 y ss.

(37) Ibidem, p. 631.

(38) Discursos históricos de la ciudad de Murcia y su Reyno. Reedición facsimil de la de 1775, Ac. Alfonso X, Murcia, 1980.

(39) A. MESTRE, Historia, Fueros y actitudes politicas. Valencia, 1970, p. 253.

(40) Por Francisco Benedito, 1777-1778, 2 tomos en $4 .^{\circ}$. Cf. TEJERA, loc. cit. p. 562 y ss.

(41) Emmanuelem Muñiz, 1794, 167 p. más 60 h. en $4 .^{\circ}$. Cf. TEJERA, loc. cit. p. 539.

(42) Sin impr., 1776 ?, 48 p. en fol. Cf. TEJERA, loc. cit. p. 414.

(43) Sin impr. 1796, 14 h. en folio. Cf. TEJERA, loc. cit., p. 439.

(44) D. Félix de Copons, Instrucción moral... que el Teniente Coronel D. dexó a su hijo... por Antonio Santamaria, 1784, 148 p. más 6 h. en 8. ${ }^{\circ}$. Cf. TEJERA, loc. cit. p. 292.

(45) DIEZ y EGEA, op. cit. pp. 58-63.

(46) Ibidem.

(47) TEJERA, IOc. cit. p. 725.

(48) Por Phelippe Diaz, s. a., 87 p. más 4 h. en $4 .^{\circ}$, Cf. TEJERA loc cit., p. 424.

(49) Por Francisco Benedito. Cf. TEJERA, loc. cit., p. 403-404.

(50) Por citar un dato, destaquemos el no corto número de tragedias que vieron la luz durante estos años.

(51) Nos remitimos a la conocida obra de M. DEFOURNEAUX, Inquisición y censura de libros en la España del siglo XVIII, Madrid, Taurus, 1973.

(52) Cf. P. J. GUINARD, La presse espagnole de 1737 a 1791. Formation et signification d'un genre. Centre de Recherches Hispaniques, Paris, 1973.

(53) Excepción hecha de la Gazeta de Murcia, aparecida en 1706, y del Semanario Literario y Curioso de Cartagena. Cf. J. HERNANDEZ FRANCO, "El Diario de Murcia, estudio analiticosocial de un periódico ilustrado", Anales Universidad de Murcia, Letras vol. XXXVIII, n. ${ }^{\circ} 4,1979$ 80 , pp. 49-64. 
(54) Vid. las listas publicadas sucesivamente en los números del propio periódico. Cf. un estudio parcial en nuestra comunicación al VII Congreso de Historia de la Medicina, "Periodismo ilustrado en Murcia: el Correo Literarion, Alicante, 1983 (en prensa).

(55) Cf. FLORES ARROYUELO, loc. cit. y J. BALLESTER NICOLAS, Amanecer de la prensa periodica en Murcia, Ac. Alfonso X, Murcia, 1971.

(56) P. J. GUINARD, op. cit.

(57) Los números del Correo pueden consultarse, excepto un tomo desaparecido, en el Archivo del Ayuntamiento de Murcia.

(58) A. ELORZA, "Liberalismo económico y sociedad estamental a fines del siglo XVIIl", Moneda y Crédito, 110, 1969, pp. 91-111.

(59) J. M. LOPEZ PIÑERO, La Introducción de la Ciencia moderna en España, Ariel, BarceIona, 1969.

(60) Por la Vda. de Felipe Teruel, 1782, en $4 .^{\circ}$. Cf. TEJERA, loc. cit., p. 518.

(61) Publicados en 1793 y 1788, respectivamente, por la Vda. de Felipe Teruel. Cf. TEJERA, loc. cit. pp. 234-235.

(62) Cf. nuestro artículo sobre el Seminario de San Fulgencio.

(63) Es decir, 130 son escritores ocasionales. En cuanto a la prolijidad de Belluga y de Santos Alonso, habría que tener en cuenta múltiples factores para medirla con justicia, en especial en el caso del segundo, por tratarse de cortos folletos.

(64) Cf. DIEZ y EGEA, op. cit., p. 56.

(65) Una buena síntesis y bibliografía en L. GIL, Panorama social del Humanismo español, Madrid, Alhambra, 1981. Vid. en especial su parte $V$.

(66) Loc. cit., pp. 624-635.

(67) Loc. cit., pp. 723-725.

(68) Cf. F. LOPEZ, "Lisants et lecteurs en Espagne au XVIIleme. siécle. Ebauche d'une problematique", en las Actas del Coloquio celebrado en la Casa de Velázquez sobre Livre et lecture en Espagne et en France sous l'Ancien Regime, Paris, 1981, p. 146.

(69) M. L. LOPEZ TERRADA, La literatura Cientifica en la Valencia de la llustración (17001808). Tesina de Licenciatura, Facultad de Geiografía e Historia, Valencia, 1982.

(70) Novisima Recopilación, Libro VIII, Título XIV, Ley V, 16-mayo de 1766.

(71) TEJUERA, loc. cit. pp. 611-623.

(72) Ibid., p. 616.

(73) Ibid., pp. 624 y ss.

(75) J. HERNANDEZ FRANCO, op. cit., p. 59.

(76) A. H. N. Consejos, leg. 5560(1), expte. 86 «Don Luis Santiago Bado sobre que se le permita continuar publicando los dos periódicos que expresan.

(77) A. H. N. Consejos, leg. 5696, año 1815, "Diligencia de visita...”. 